\title{
Enhanced Oil Recovery from Austin Chalk Carbonate Reservoirs Using Faujasite-based Nanoparticles Combined with Low Salinity Water Flooding
}

Moussa Taleb, Farad Sagala, Afif Hethnawi, Nashaat N. Nassar*

Department of Chemical and Petroleum Engineering, University of Calgary, Calgary, Alberta, Canada, T2N 1 N4

*(Tel.: +1 (403) 210-9772, Fax: +1 (403) 210-3973, E-mail: nassar@ucalgary.ca)

\section{LIST OF SUPPORTING FIGURES}

Figure S1. XRD for the rock sample

Figure S2. The viscosity of oil as a function of temperature

Figure S3. Austin Chalk core samples used in the study

Figure S4. Carbonate substrates used in contact angle measurements after ageing in crude oil.

Figure S5. XRD pattern of Na-FAU-based nanoparticles. Vertical lines are the reference data (Faujasite, $\left.\mathrm{Na}_{71}\left(\mathrm{Si}_{121} \mathrm{Al}_{71}\right) \mathrm{O}_{384}\right)$ from Materials Data XRD Pattern Processing Identification \& Quantification.

Figure S6. Pore size distribution (PSD) of the Y-type FAU zeolite 


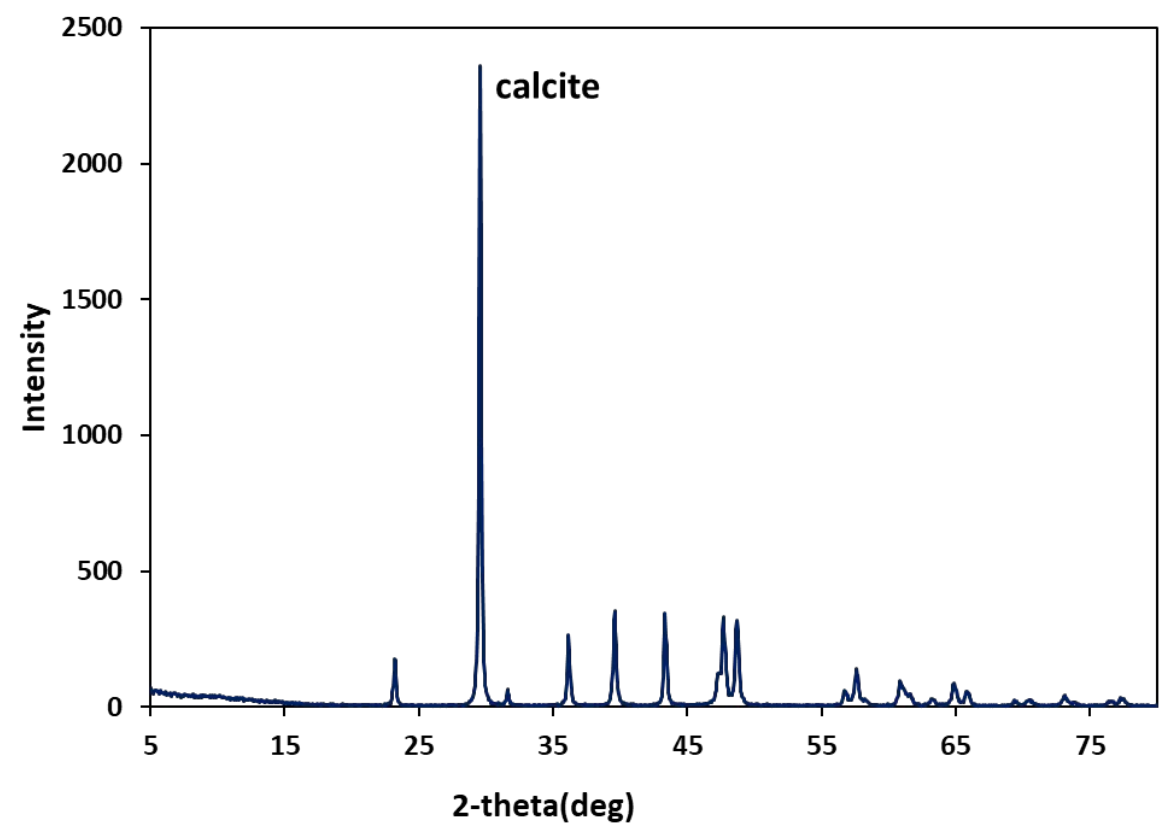

Figure S1. XRD for the rock sample

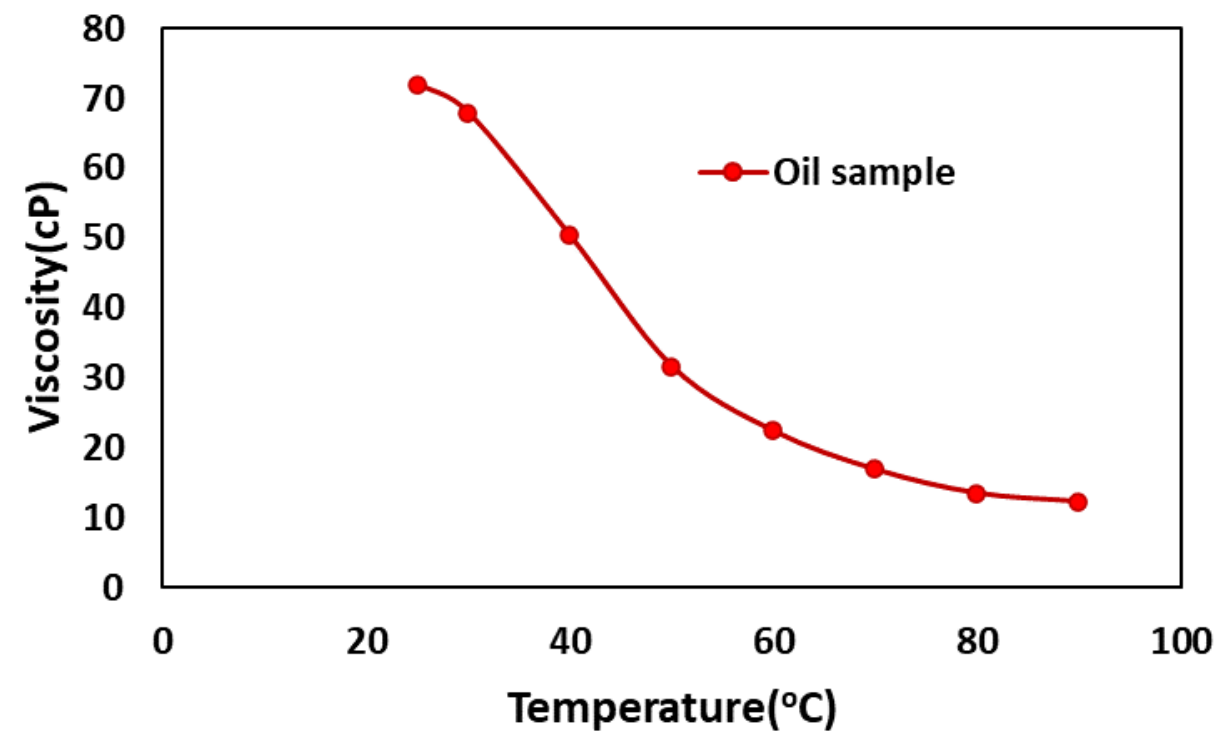

Figure S2. The viscosity of oil as a function of temperature 


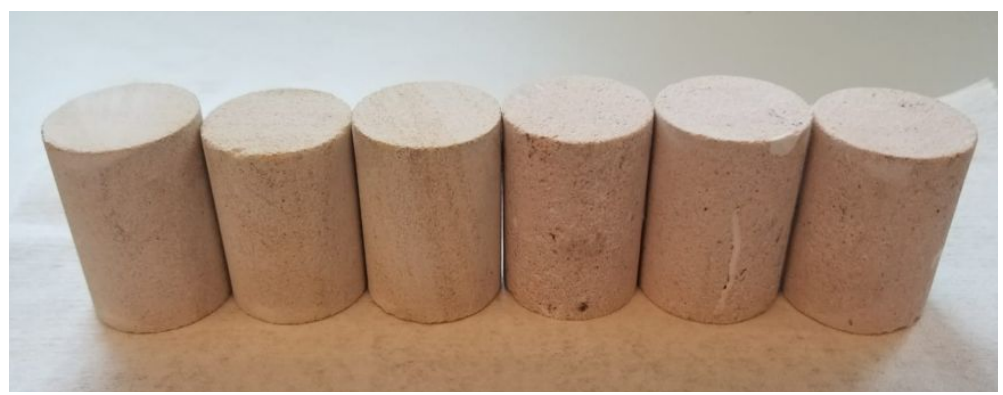

Figure S3. Austin Chalk core samples used in the study

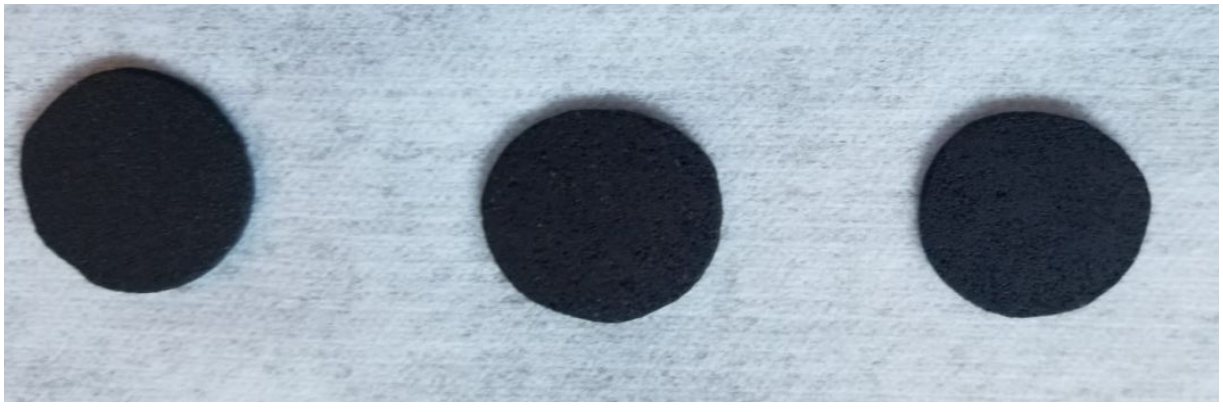

Figure S4. Carbonate substrates used in contact angle measurements after ageing in crude oil. 


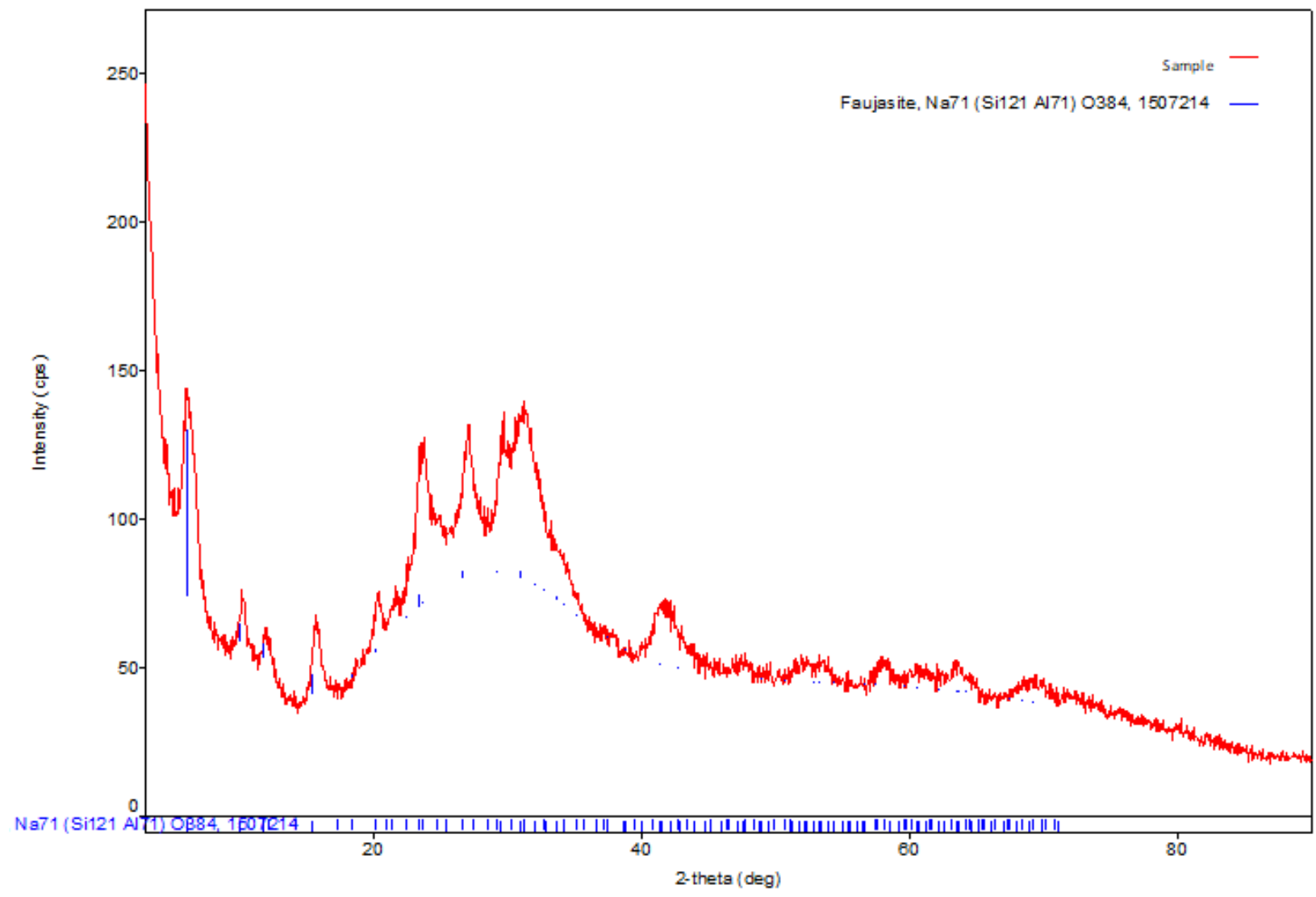

Figure S5. XRD pattern of Na-FAU-based nanoparticles. Vertical lines are the reference data (Faujasite, $\left.\mathrm{Na}_{71}\left(\mathrm{Si}_{121} \mathrm{Al}_{71}\right) \mathrm{O}_{384}\right)$ from Materials Data XRD Pattern Processing Identification \& Quantification. 


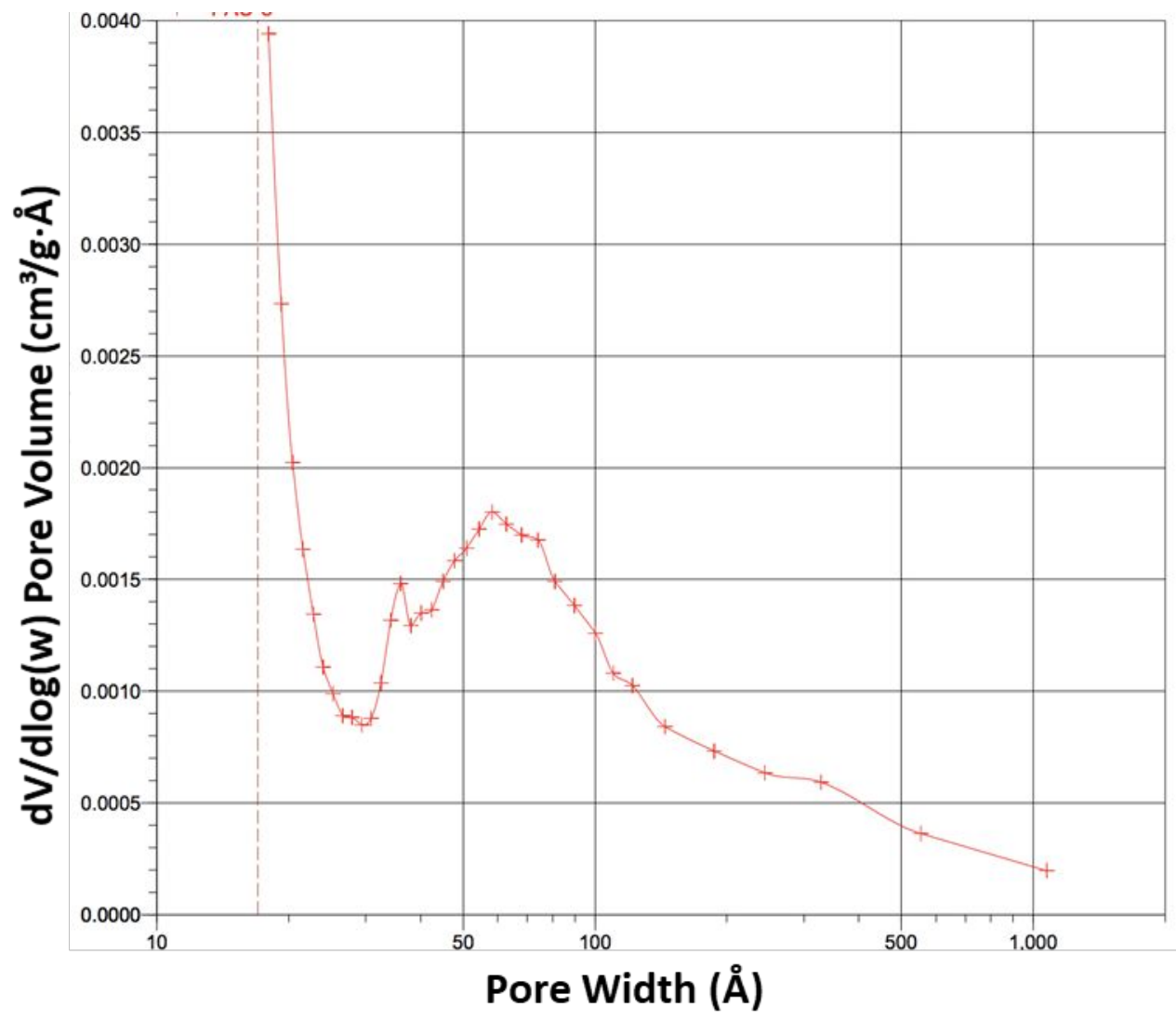

Figure S6. Pore size distribution (PSD) of the Y-type FAU zeolite. 